\title{
Prostate cancer outcome in Burkina Faso
}

\author{
Fasnéwindé A Kabore ${ }^{1 *}$, Barnabé Zango ${ }^{1}$, Adama Sanou ${ }^{2}$, Clotaire Yameogo ${ }^{1}$, Brahima Kirakoya ${ }^{1}$ \\ From The Science of Global Prostate Cancer Disparities in Black Men \\ Jacksonville, FL, USA. 27-29 August 2010
}

\begin{abstract}
Introduction: African-American black men race is one of non-modifiable risk factors confirmed for prostate cancer. Many studies have been done in USA among African- American population to evaluate prostate cancer disparities. Compared to the USA very few data are available for prostate cancer in Sub-Saharan African countries. The objective of this study was to describe incident prostate cancer (PC) diagnosis characteristics in Burkina Faso (West Africa).

Methods: We performed a prospective non randomized patient's cohort study of new prostate cancer cases diagnosed by histological analysis of transrectal prostate biopsies in Burkina Faso. Study participants included 166 patients recruited at the urology division of the university hospital of Ouagadougou. Age of the patients, clinical symptoms, digital rectal examination (DRE) result, serum prostate-specific antigen (PSA) level, histological characteristics and TNM classification were taking in account in this study.

Results: 166 transrectal prostate biopsies (TRPB) were performed based on high PSA level or abnormal DRE. The prostate cancer rate on those TRPB was $63,8 \%(n=106)$. The mean age of the patients was 71,5 years (52 to 86). Urinary retention was the first clinical patterns of reference in our institution $(55,7 \%, \mathrm{n}=59)$. Most patients, 56,6 $\%(n=60)$ had a serum PSA level over than $100 \mathrm{ng} / \mathrm{ml}$. All the patients had adenocarcinoma on histological study of prostate biopsy cores. The majority of cases $(54,7 \% \mathrm{n}=58)$ had Gleason score equal or higher than 7 .
\end{abstract}

Conclusion: Prostate cancer is diagnosed at later stages in our country. Very high serum PSA level and poorly differentiated tumors are the two major characteristics of PC at the time of diagnosis.

\section{Introduction}

African-American black men race is one of non-modifiable risk factors confirmed for prostate cancer (PC). Many studies have been done in USA among African-American to evaluate prostate cancer disparities in this population. African-Americans have more advanced stages of PC at diagnosis and higher mortality rates for PC than whites. [1-4] There is no scientific proof that PC in AfricanAmericans has the same characteristics in their ancestry from Central and West Africa but there is documented evidence in the literature indicating that prostate cancer in one West African country, Nigeria, is similar to rates found in the United States [5]. Compared to the USA very few data are available for prostate cancer in Sub-Saharan

\footnotetext{
* Correspondence: ristof78@hotmail.com

'Division of urology, Yalgado Ouédraogo University hospital of

Ouagadougou 03 Po Box 7022, Burkina Faso

Full list of author information is available at the end of the article
}

African countries [1,2]. This work aims to contribute by providing more data about PC in West Africa and to participate in the research to reduce prostate cancer disparities in black men. In Burkina Faso (West Africa) PC epidemiology, clinical and pathological characteristics are not well evaluated. This study is the first to assess PC particularity at the biggest urology division in the university hospital of the main city of Burkina Faso: Ouagadougou. The objective of the study was to describe PC diagnosis characteristics at the time of diagnosis in our country.

\section{Methods}

We performed a prospective non randomized patient's cohort study of new PC cases diagnosed in Burkina Faso. Study participants included 166 patients recruited at the urology division of the university hospital of Ouagadougou. Our institution receives patients from all over the country. PC cases were diagnosed at histological analysis 
of transrectal prostate biopsy (TRPB) core among 166 patients who had abnormal digital rectal examination (DRE) or high serum prostate-specific antigen (PSA) level. The recruitment of all patients was made between January 2009 and June 2010. The variables of interest included age at diagnosis, the clinical symptoms of reference in our center for PC, serum PSA level, information about prostate biopsy (histological type, Gleason score) and stage of tumor determined according to the TNM 2007 classification. The existence of metastatic PC was evaluated with clinical exam and thoraco-abdominal and pelvis computed tomography. Descriptive statistics were used to summarize these variables in terms of the means, extremes values, and frequencies.

\section{Results}

One hundred and sixty six (166) TRPB were performed based on high PSA level or abnormal DRE. The prostate cancer rate on those TRPB was $63,8 \%(n=106)$. The mean age of the patients was 71,5 years (52 to 86). All patients had abnormal DRE. Figure 1 summarizes the clinical symptoms at the time of diagnosis. The mean duration of symptoms prior to presentation was 12.6 months (range: 1 month to 6 years). Urinary retention was the first clinical patterns of reference in our institution $(55,7 \%, \mathrm{n}=59)$. Most patients, 56, 6\% $(\mathrm{n}=60)$ had a serum PSA level over than $100 \mathrm{ng} / \mathrm{ml}$ [figure 2]. The mean serum PSA level was $537 \mathrm{ng} / \mathrm{ml}(8,41$ to 17850). All the patients had adenocarcinoma on histological study of prostate biopsy cores. The majority of cases $(54,7 \% \mathrm{n}=58)$ had Gleason score equal or higher than 7 [Figure 3]. Most patients, 73, $6 \%(n=78)$ had their primary tumor extended over the prostatic capsule (T3-T4 stages). Table 1 summarizes the lymph nodes $(\mathrm{N})$ involvement and metastatic $\mathrm{PC}(\mathrm{M})$ according to primary tumor stage $(\mathrm{T})$.

\section{Discussion}

Numerous studies have reported that black men are diagnosed with prostate cancer at a younger age $[3,6]$ than white men. Many other studies suggest that there are no age differences at the time of PC diagnosis [4,7]. In our study the mean age is higher $(71,5)$. Older age at the time of diagnosis of PC is commonly reported from West Africa [8-11]. The majority of patients in this study $(84 \%)$ presented urinary retention or lower urinary tract symptoms (LUTS). According to Ajapé [8] the severity of urinary symptoms at the time of PC diagnosis in low resources countries is relevant to late presentation, ignorance of the population concerning PC symptoms, and poverty. Furthermore, the lack of urology centers (only two public urology centers in Burkina Faso) can be a reason of late presentation.

Studies have reported that African-American men diagnosed with prostate cancer have greater PSA levels than whites $[3,9,12,13]$. The results of our study strengthen these reports. However the mean PSA level in our study is very high. This is relevant to late presentation and the fact that several patients included in this study were empirically managed for several years for PC without PSA testing or biopsy in poorly equipped rural centers. However we cannot exclude a possible "racialethnical" particularity in our country but this must be assessed by further studies. The relation between high PSA level in black men, race and genetic is not well established. Veda [12] finds no evidence in support of the traditional "race-specific" PSA. He reports that the PSA has a higher prediction for PC in African-American

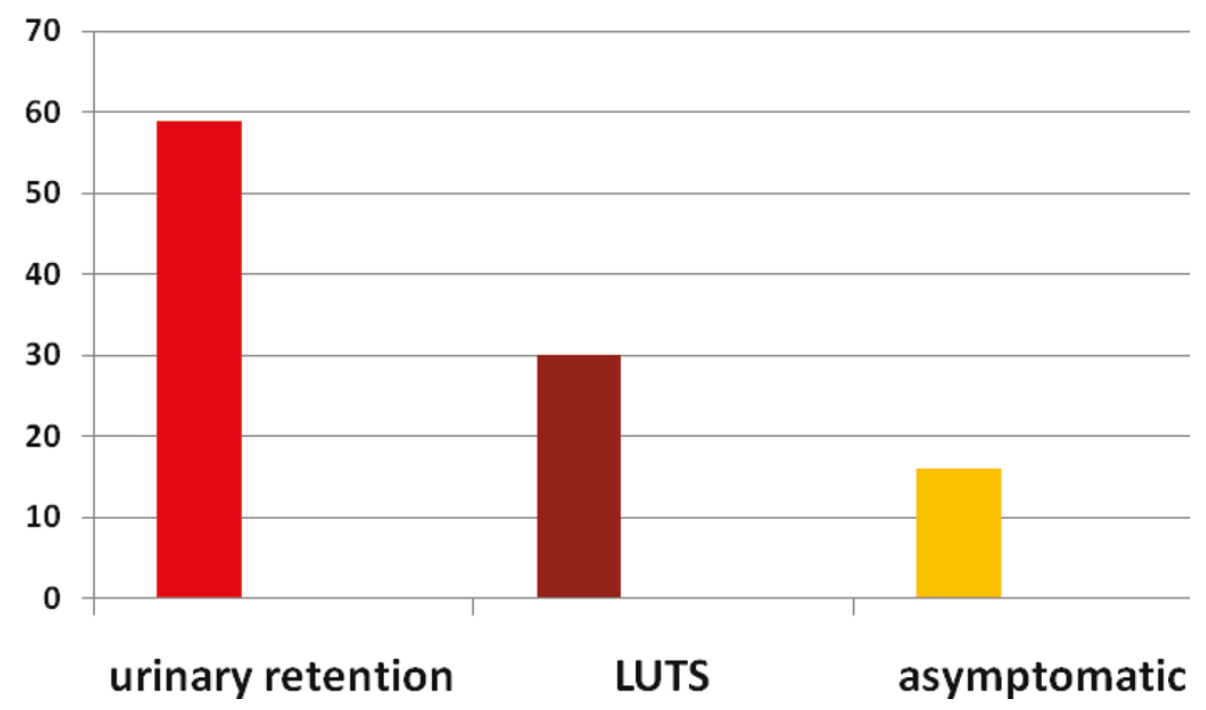

Figure 1 Repartition of patients according to Clinical symptoms 


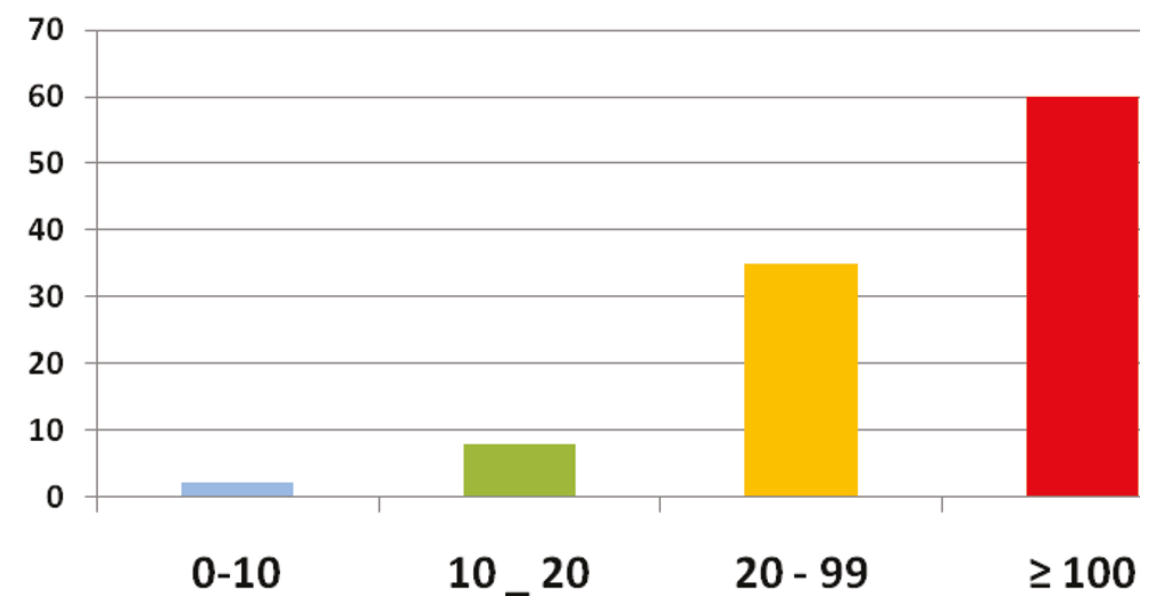

Figure 2 Repartition of patients according to Serum PSA level

men but concludes that this finding may be explained by genetic West African ancestry which needs further study.

Most PC cases reported in our study were high grade tumors with poor prognosis (PSA $>20 \mathrm{ng} / \mathrm{ml}$, Gleason score 7-10, or clinical stage T3-T4). The explanation is late diagnosis and the lack of PC screening program in our country. The Gleason score is the most reliable factor in determining the biological characteristics of prostate cancer, tumor stage, and its prognosis. [3,14] Several reports that black men presented with more poorly differentiated PC than white. $[2,3,15]$ These results suggest more studies to evaluate if other factors such as diet, lifestyle, genetics played a role in high Gleason score reported in black men prior to late diagnosis and limited access to medical center.
PC screening remains controversial and expose to over diagnosis and overtreatment. In a recent review, Stavridis [16] concludes that, as we are aware, there is no sufficient evidence to recommend routine population screening for PC. Nevertheless, clinicians should provide information about potential benefits and risks of screening for $\mathrm{PC}$, and the limitations of current evidence for screening, and make the final decision to screen or not. However, screening has the potential to reduce PC disparities in African black men. A good PC screening policy in Burkina Faso can reduce specific mortality by early diagnosis and raise the population awareness of PC. Arthur [17] in Ghana promotes screening to improve early detection, management and prognosis of PC.

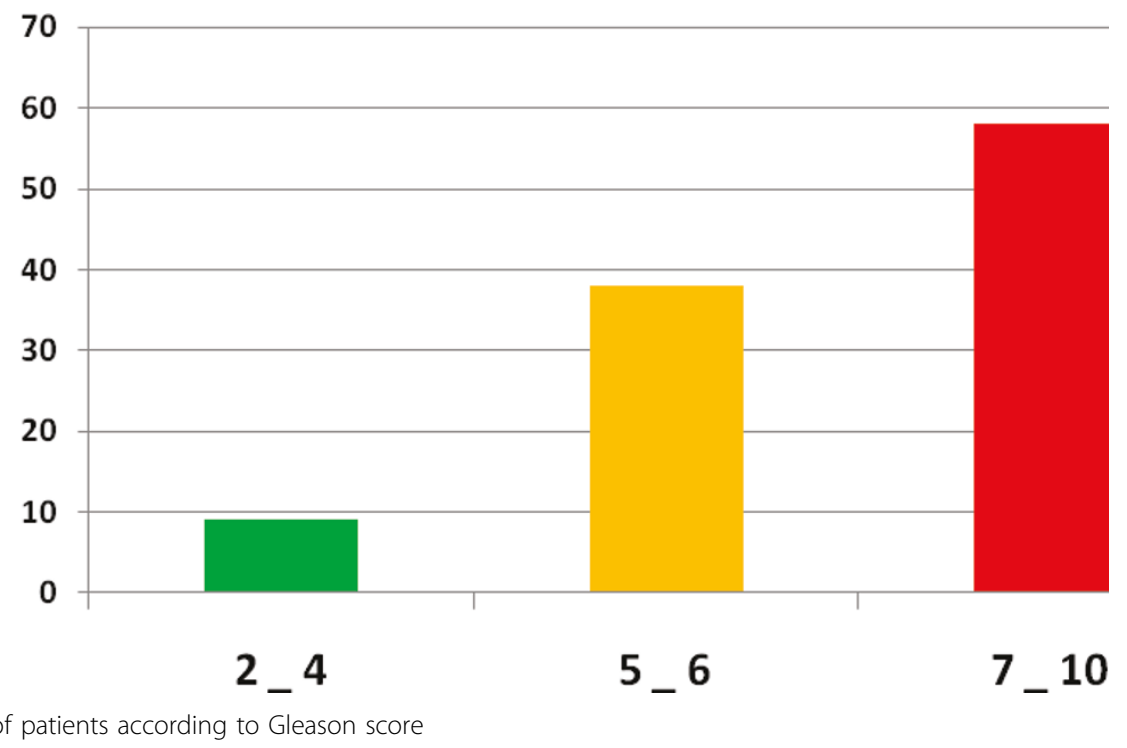

Figure 3 Repartition of patients according to Gleason score 
Table 1 Lymph nodes involvement and metastatics localizations according to primary tumor stage

\begin{tabular}{lccc}
\hline Primary tumor (T) & $\mathbf{n} / \%$ & Lymph node Involvement $(\mathbf{N}) \mathbf{n} / \%$ & Metastatic Localization (M) $\mathbf{n} / \%$ \\
\hline T1 & $0 / 0$ & $0 / 0$ & $0 / 0$ \\
T2 & $28 / 26,4$ & $3 / 2,8$ & $0 / 0$ \\
T3 & $40 / 37,7$ & $12 / 11,3$ & $12 / 11,3$ \\
T4 & $38 / 35,9$ & $30 / 28,3$ & $32 / 30,2$ \\
\hline Total & $\mathbf{1 0 6 / 1 0 0}$ & $\mathbf{4 5 / 4 2 , 4}$ & $\mathbf{4 4 / 4 1 , 5}$ \\
\hline
\end{tabular}

\section{Conclusion}

$\mathrm{PC}$ is diagnosed at later stages in Burkina Faso. Very high serum PSA level and poorly differentiated tumors are the two major characteristics of $\mathrm{PC}$ at the time of diagnosis. Interventions focused on screening, education about the disease and early detection could substantially improve these findings. This work suggests more studies are needed in this country to better access PC epidemiology, genetics, mortality and survival particularities.

\section{Acknowledgements}

many thanks to the organization staff and all the attendees of the first biennale conference of science of global prostate cancer disparities in Black Men, August 27-29, 2010 in Jacksonville, Florida, USA.

This article has been published as part of Infectious Agents and Cancer Volume 6 Supplement 2, 2011: Proceedings of the First Biennial Conference on the Science of Global Prostate Cancer Disparities in Black Men. The full contents of the supplement are available online at http://www. infectagentscancer.com/supplements/6/S2.

\section{Author details}

'Division of urology, Yalgado Ouédraogo University hospital of Ouagadougou 03 Po Box 7022, Burkina Faso. ${ }^{2}$ Division of general surgery Yalgado Ouédraogo University hospital of Ouagadougou 03 Po Box 7022, Burkina Faso.

\section{Authors' contributions}

FAK conceptualized, designed the study and wrote the paper. ZB, CY, AS and BK participated in data collection and reviewed the manuscript. All the authors reviewed and approved the manuscript.

\section{Competing interests}

No competing interests.

Published: 23 September 2011

\section{References}

1. Folakemi TO, Titilola OA, Frank C, Robin R, Daohai Y, Renee R, Matthew LF, Brian R, Lee G, Nagi K: Prostate cancer disparities in Black men of African descent: a comparative literature review of prostate cancer burden among Black men in the United States, Caribbean, United Kingdom, and West Africa. Infect Agent Cancer 2009, 4(Suppl 1):S2.

2. Gueye SM, Zeigler-Johnson CM, Friebel T, Spangler E, Jalloh M, et al: Clinical characteristics of prostate cancer in African Americans, American whites, and Senegalese men. Urology 2003, 61:987-92.

3. Stephen JF, Mark ES, John N, Frederick D, George SC, William JA: Clinical characteristics in black and white men with prostate cancer in an equal access medical center. Urology 2000, 55:387-390.

4. Milton SB, Venceslau RS, Gladston BS, Alexandre H, Marco AS: Prevalence of prostate adenocarcinoma according to race in an university hospital. Int Braz J Urol 2003, 29:306-12.

5. Folakemi TO, Olufemi OJ, Flora AMU: Roots of Prostate Cancer in AfricanAmerican Men. J Natl Med Assoc 2006, 98:539-43.
6. Ravery $V$, Javerliat I, Toublanc $M$, et al: Characteristics of prostate cancers in french men of African and Caribbean origin. Prog Urol 2000, 10:231-236.

7. Jeannette MP, Megan L, Esteban W, Charles M, Eric K: Trends in PSA, age and prostate cancer detection among black and white men from 19902006 at a tertiary care center. Cancer 2010, 116:3910-5.

8. Ajape AA, Ibrahim KO, Fakeye JA, Abiola OO: An overview of cancer of the prostate diagnosis and management in Nigeria: The experience in a Nigerian tertiary hospital. Ann Afr Med 2010, 9:113-17.

9. Gueye SM, Jalloh M, Labou I, Niang L, Kane R, Ndoye M: Clinical Profile of Prostate Cancer in Senegal. Afr.J.Urol. 2004, 10:203-7.

10. Diallo AB, Bah I, Barry AM, Youwe Dombeu N, Barry M, Diallo MB: Epidemiological features of prostate cancer in the Republic of Guinea. Afr.J.Urol. 2008, 14:161-7.

11. Nwofor AM, Oranusi CK: Cancer of the prostate: Experience at Nnewi, Southeast, Nigeria. Niger J Clin Pract 2004, 7:65-8.

12. Veda NG, Brian E, Karen R, Robert GU, David YTC, Mark B, Susan R, Stanley H, Jada BT, Teniel R, Kathleen M, Taylor YK, Rick K: Race, genetic West African ancestry, and prostate cancer prediction by PSA in prospectively screened high-risk men. Cancer Prev Res (Phila) 2009, 2:244-50.

13. Morgan TO, Jacobsen SJ, Mc Carthy WF, et al: Age specific reference ranges for serum prostate specific antigen in black men. $N$ Engl J Med 1996, 335:304-10.

14. Seung JM, Sung YP, Tchun YL: Predictive factors of gleason score upgrading in localized and locally advanced prostate cancer diagnosed by prostate biopsy. Korean J Urol 2010, 51:677-82.

15. Shirley SE, Escofferey CT, Sargeant LA, et al: Clinicopathological features of prostate cancer in Jamaican men. BJU Int 2002, 89:390-5.

16. Stavridis S, Saidi S, Lekovski Lj, Dohcev S, Spasovski G: Screening for prostate cancer: a controversy or fact. Hippokratia 2010, 14:170-5.

17. Arthur FKN, Yeboah FA, Adu-Frimpong M, Sedudzi EE, Boateng KA: Prostate cancer screening in Ghana - a clinical benefit? Journal of Science and Technology 2006, 26:1-7.

doi:10.1186/1750-9378-6-S2-S6

Cite this article as: Kabore et al:: Prostate cancer outcome in Burkina

Faso. Infectious Agents and Cancer 2011 6(Suppl 2):S6.

\section{Submit your next manuscript to BioMed Central and take full advantage of:}

- Convenient online submission

- Thorough peer review

- No space constraints or color figure charges

- Immediate publication on acceptance

- Inclusion in PubMed, CAS, Scopus and Google Scholar

- Research which is freely available for redistribution

Submit your manuscript at www.biomedcentral.com/submit 